\section{Determinant factors, trend and outcomes of cesarean delivery in Debre Berhan referral hospital, North Shewa Zone, Ethiopia}

\author{
Tsegahun Asfaw, Alemnesh Tesema \\ Department of Medical Laboratory \\ Science, Debre Berhan University, Debre \\ Berhan, Ethiopia
}

\begin{abstract}
Cesarean Section (CS) refers to the delivery of a fetus, placenta and membrane through the abdominal and uterine incision after 28 weeks of gestation. Unless used appropriately, the potential risk to the mother and baby becomes more than the vaginal delivery. Therefore, this study is designed to assess the determinant factors, trends and outcomes of caesarean delivery. Hospital based cross-sectional study was conducted from January 2015 to December 2016. All cesarean deliveries performed after period of viability ( 28 weeks) were included. The data was collected by using checklist and pretested questionnaire. The data was entered into EpiData and analyzed by SPSS version 21. There were 2587 deliveries in 2015 and 3423 deliveries in 2016, from those 440 and 660 were delivered by CS in each year respectively. The rate of CS in 2015 and 2016 was $17 \%$ and $19.3 \%$ respectively. The most common indication of CS was fetal distress. Mothers who had no antenatal care (ANC) follow-up had 3.16 times more risk for fetal death than mothers having ANC follow-up. We can conclude that the cesarean delivery rate is greater than WHO recommendation. ANC follow-up, parity, duration of labor, gestational age, types of CS and types of anesthesia are the main risk factors for CS and influence maternal and fetal outcomes.
\end{abstract}

\section{Introduction}

Cesarean Section (CS) refers to the delivery of fetus, placenta and membrane through the abdominal and uterine incision after 28 weeks of gestation. It is the most common major surgical procedure used and it has helped to decrease maternal and fetal mortality and morbidity. CS is usually performed when a vaginal delivery would put the mother and baby's life at risk but sometimes it is also performed on request. ${ }^{1}$

Currently it is estimated that about 20 million CS deliveries occur each year in the world. The number of women having babies born by $\mathrm{CS}$ is rapidly growing in a continuous way both in developed and developing countries. CS is one of the lifesaving surgical intervention attribute to the decrease of maternal and perinatal mortality and morbidity. ${ }^{2}$

The World Health Organization (WHO) states that the rate of $\mathrm{CS}$ should be at maximum of $15 \%$ and no region in the world is justified with having a cesarean rate greater than $10 \%$ to $15 \%$ and not be less than $5 \% .3,4$ Newborns delivered by planned or scheduled cesarean are at increased risk of respiratory and other morbidity compared with newborns delivered vaginally or by emergent cesarean. The optimum time for repeat cesarean delivery appears to be at 39 to 40 weeks of gestation. Compared to earlier (37 to 38 weeks) or later ( $\geq 41$ weeks) delivery, scheduled delivery during the 39 th or 40th week results in the lowest rate of adverse neonatal outcomes.

\section{Materials and Methods}

\section{Study area and study design}

Cross-sectional study design was conducted from January 2015 to December 2016 at Debre Berhan referral hospital. This hospital is located $130 \mathrm{kms}$ north of Addis Ababa. It has 130 beds. Maternity and Gynecological services are the main surgical procedures.

\section{Inclusion and exclusion criteria}

All cesarean deliveries performed after the period of viability ( 28 weeks) including elective, emergency, primary and repeat cases were included, while cesarean deliveries which were not fully documented and those for those women for whom CS was done before 28 weeks of gestation were excluded.

\section{Data collection and processing}

The socio-demographic and clinical data was collected by using checklist and pretested questionnaire by well-trained physicians and nurses. Finally, the data was entered into EpiData and analyzed by SPSS version 21 .

\section{Data quality control}

The checklist was checked for its clarity, completeness and consistency by the data collectors. Patients' individual chart was cross checked with operation room and delivery room registration book continuously.
Correspondence: Tsegahun Asfaw, Department of Medical Laboratory Science, Debre Berhan University, P.O. Box: 445 Debre Berhan, Ethiopia.

Tel.: +251910133613

E-mail: tsegahun.asfaw12@gmail.com

Key words: Cesarean Delivery, Determinant Factors, Tends, Outcomes.

Contributions: Data curation: TA and AT; Formal analysis: $\mathrm{TA}$ and $\mathrm{AT}$; Investigation: $\mathrm{TA}$; Supervision: TA; Writing original draft: TA; Writing-review \& editing: TA and AT.

Conflict of interest: The authors declare no conflict of interest.

Funding: None.

Data availability: All data are included in the manuscript. Raw data is available upon request.

Consent: A written informed consent was requested from the participant mothers. For illiterate mothers, the consent information sheet was read out loud in full and requested to thumbprint to signify their willingness to participate. Participants were asked to participate voluntarily, and those who were not willing to participate were also given standard care as per facility protocols.

Ethical approval: Ethical approval was obtained from Research and Review Committee of Debre Berhan University. Official permission was obtained from head department of Debre Berhan referral Hospital.

Received for publication: 19 December 2019. Revision received: 23 February 2020. Accepted for publication: 24 February 2020.

This work is licensed under a Creative Commons Attribution NonCommercial 4.0 License (CC BY-NC 4.0).

(C) Copyright: the Author(s), 2020

Licensee PAGEPress, Italy

Pediatric Reports 2020; 12:8430

doi:10.4081/pr.2020.8430

\section{Results}

\section{Socio-demographic characteristics}

There were 2587 deliveries in 2015 and 3423 deliveries in 2016, from those 440 and 660 were delivered by CS in each year respectively. The prevalence of CS in 2015 and 2016 was $17 \%$ and $19.3 \%$ respectively. Therefore, there is a total of 6010 deliveries in two consecutive years, of which 1100 (18.3\%) were delivered by CS. The maternal age was from 15-49 years old with the mean age of 27 years old \pm 5.33 SD. Majority of 
them were within 25-29 years old, 459 (41.8\%) followed by $20-24$ years old, 261 $(23.9 \%)$. Around $1064(96.7 \%)$ of the mothers were married and $797(72.5 \%)$ of the mothers were orthodox religion followers (Table 1).

\section{Obstetric characteristics}

Mothers with one to four previous pregnancies (p) were $1020(92.7 \%)$ and the rest $80(7.3 \%)$ already had five or more pregnancies. The majority of them 1003 $(91.2 \%)$ were between $\mathrm{p} 1$ and $\mathrm{p} 4$ and 97 $(8.8 \%)$ of the mothers had five or more delivery history. The common gestational age category for CS was 38-42 weeks (Table 2). Mothers who had ANC follow up were $1011(91.9 \%)$, of which $991(98 \%)$ of them had greater than or equal to two ANC visit before delivery. Most of the current pregnancy were singleton $1040(94.5 \%)$ and $60(5.5 \%)$ were multiple pregnancy, of which $59(98.4 \%)$ were twins and $1(1.6 \%)$ was triplets (Table 3).

Among multiple pregnancy, 34 (56.67\%) were breech presentation and 26 $(43.33 \%)$ of them were cephalic. Majority of the mothers $(333,30.6 \%)$ had been in labor before CS for 12-17 hours. Around 949 $(86.3 \%)$ of fetal presentation were cephalic then followed by breech presentation (Table 4). The most common indications of cesarean delivery were Non-Reassuring Fetal Heart Rate (NRFHR) pattern 301(27.4\%), followed by CPD $116(10.5 \%)$, failed induction 114(10.4\%), previous CS scar 109(9.9\%), preeclampsia-eclampsia 102 (9.3\%), APH 82 (7.5\%) and malposition 54 (4.9\%) (Figure 1).

\section{Maternal and fetal outcome charac- teristics}

Out of 1100 reviewed chart 918 (83.4\%) women have no complication, while 182 $(16.5 \%)$ have complication like vaginal bleeding 61 (33.5\%), severe abdominal pain $53(29.1 \%)$, surgical site infection $39(21.4 \%)$ (Table 5).

The main causes of complication were delay in intervention $55(55.5 \%)$ and

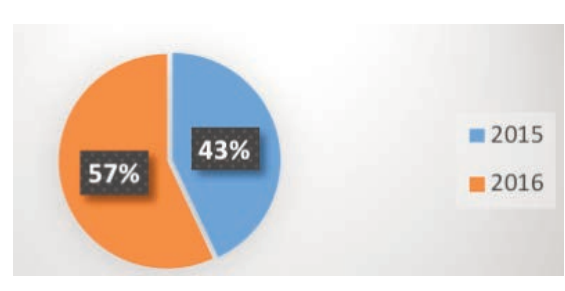

Figure 1. Distribution of cesarean delivery indications at DBRH from January, 2015 to December, 2016. unspecified cause 29 (29\%). The common anesthesia type used in this study was spinal anesthesia $853(77.6 \%)$ and general anesthesia 247 (22.4\%). The most common type of CS was LUSTCS 1096 (99.6\%) followed by classic type $4(0.4 \%)$. Among mothers, 1001(91.9\%) were give live birth and $99(0.9 \%)$ were give dead fetus after cesarean delivery (Table 6).

Among mother's majority of last pregnancy had spontaneous vaginal delivery (SVD) 540 (82.3\%) followed by CS 116 (17.7 \%). Among CS delivery, 76 (65.5\%) women have one times previous CS scar and $27(23.3 \%)$ mothers have two times previous CS scar. Among 1100 mothers, 198 (18\%) were anemic (there hemoglobin levels were between $4-11 \mathrm{mg} / \mathrm{dL})$, whereas 902 (82\%) of them were above $11 \mathrm{mg} / \mathrm{dL}$. Among 1081 (98\%) women were tested for HIV, 58 $(5.3 \%)$ of them were HIV positive (Table 7 ).

Table 1. Distribution of age, marital status and religion of mothers at DBRH from January 2015 to December 2016.

\begin{tabular}{lcc} 
& Frequency & Percent \\
Age of the mother & & \\
$15-19$ & & 37 \\
3.4 & & \\
$20-24$ & 263 & 23.9 \\
$25-29$ & 459 & 41.8 \\
$30-34$ & 197 & 17.9 \\
$>34$ & 144 & 13.1 \\
Total & 1100 & 1100 \\
Marital status & & \\
Married & 1064 & 96.7 \\
Divorced & 11 & 1 \\
Widowed & 3 & .3 \\
Single & 22 & 2 \\
Total & 1100 & 1100 \\
\hline Religions & & \\
Orthodox & 797 & 72.5 \\
Muslim & 250 & 22.7 \\
Catholic & 11 & .9 \\
Protestant & 42 & 3.8 \\
Total & 1100 & 1100 \\
\hline
\end{tabular}

Table 2. Distribution of gravidity, parity and gestational age of mothers at DBRH from January 2015 to December 2016.

\begin{tabular}{llc} 
Variable & & Frequency \\
Gravidity & G1-G4 & 1020 \\
& G5-G9 & 80 \\
& Total & 1100 \\
Parity & P1-P4 & 1003 \\
& P5-P9 & 97 \\
& Total & 1100 \\
\hline Gestational Age & $28-32$ & 17 \\
in weeks & $33-37$ & 377 \\
& $38-42$ & 673 \\
& $43-47$ & 33 \\
Total & & 1100 \\
\hline
\end{tabular}

Table 3. Distribution of ANC follow up, number of ANC visits, pregnancy types at DBRH from January 2015 to December 2016.

\begin{tabular}{llc} 
Variable & & Frequency \\
ANC follow up & Yes & 1011 \\
& No & 89 \\
& Total & 1100 \\
No of ANC visit & $1 \mathrm{x}$ & 20 \\
& $>3 \mathrm{x}$ & 991 \\
& Total & 1011 \\
\hline Pregnancy type & Singleton & 1040 \\
& Multiple & 60 \\
& Total & 1100 \\
If multiple & Twin & 59 \\
& Triplet & 1 \\
& Total & 60 \\
\hline
\end{tabular}

Table 4. Distribution of duration of labor, fetal lie and fetal presentation for singleton pregnancies at DBRH from January 2015 to December 2016.

\begin{tabular}{llc} 
Variable & & Frequency \\
Duration of labor & $0-5$ & 225 \\
in hours & $6-11$ & 318 \\
& $12-17$ & 333 \\
& $>18$ & 218 \\
& Total & 1100 \\
Fetal lie & Longitudinal & 1069 \\
& Transverse & 31 \\
& Total & 1100 \\
\hline Fetal presentation & Cephalic & 949 \\
for single & Breech & 93 \\
& Others & 58 \\
& Total & 1100 \\
\hline
\end{tabular}

Table 5. The distribution complication after cesarean section delivery at DBRH from January 2015 to December 2016.

\begin{tabular}{llc} 
Variable & \multicolumn{2}{c}{ Frequency } \\
Post-operative & No complication & 918 \\
maternal & Complication & 182 \\
condition & Total & 1100 \\
Complication & Surgical site infection & 39 \\
& Vaginal bleeding & 61 \\
& Severe abdominal pain & 53 \\
& Others & 29 \\
& Total & 182 \\
\hline
\end{tabular}

Table 6. Types of anesthesia used during cesarean section at DBRH from January 2015 to December 2016.

\begin{tabular}{llc} 
Variable & & Frequency \\
Types of & General anesthesia & 247 \\
anesthesia & Spinal anesthesia & 853 \\
& Total & 1100 \\
\multirow{2}{*}{ Types of CS } & LUSTCS & 1096 \\
& Classic & 4 \\
& Total & 1100 \\
\hline Fetal outcome & Live birth & 1001 \\
& Died fetus & 99 \\
& Total & 1100 \\
\hline
\end{tabular}




\section{Factors associated with fetal out-} come

Mothers who had no ANC follow-up during their pregnancy period had 3.16 times more risk for fetal death than mothers having ANC follow-up (OR 3.159, P-value=0.000). Participant who were stayed in labor for greater than or equal to $12 \mathrm{hrs}$ had 1.681 times more risk for fetal death compared with from those less than $12 \mathrm{hrs}$ (OR 1.681, Pvalue $=0.015)$ ), while mothers who were anemic (blood hemoglobin $4-11 \mathrm{mg} / \mathrm{dL}$ ) had 2.533 times more risk for fetal death than from those mothers had hemoglobin level greater $11 \mathrm{mg} / \mathrm{dL}, \quad(\mathrm{OR} 2.533, \quad \mathrm{P}-$ value $=0.000)$ ) (Table 8$)$.

\section{Discussion}

In this study, among 2587 deliveries done in 2015, 440 (17\%) were CS, and among 3423 deliveries done in 2016, 660 $(19.3 \%)$ were also CS. Therefore, among 6010 deliveries, $1100(18.3 \%)$ were CS

Table 7. Distribution of previous history of delivery, HIV status and hemoglobin level of participant at DBRH from January 2015 to December 2016.

\begin{tabular}{llc} 
Variable & & Frequency \\
Previous history & SVD & 540 \\
of Delivery & CS & 116 \\
& Total & 656 \\
& No & 444 \\
No of CS & 1 Times & 76 \\
& 2 Times & 27 \\
\hline HIV status & Positive & 58 \\
& Negative & 1023 \\
Maternal hemoglobin & Not tested & 19 \\
in mg/dl & $4-11$ & 198 \\
& $>11$ & 902 \\
\hline
\end{tabular}

within 2 years. A similar study done in Finoteselam hospital, Ethiopia, among 2267 deliveries, 250 (11\%) were delivered by cesarean section. ${ }^{5}$ A study done in Attat hospital; Ethiopia shows rate of cesarean section was $27.6 \% .^{6}$ This difference might be due to the difference in awareness of study participant about CS deliveries.

Another study done in Tanzania referral hospital; the cesarean section rate ranged from $29.9 \%$ to $35.5 \% .7$ Therefore, the rate of $\mathrm{CS}$ in this study is smaller from Tanzania but greater than WHO recommendation (15\%). Generally, the reason behind for an increase in cesarean section rate of this study from WHO recommendation may be due to poor referral system, not well-established operational theatre at district hospital and the absence of adequate expert at health facilities.

The age of mothers in this study ranged from 15-45 years with a mean age of 27 years \pm 5.4 (SD). This is almost consistent with a study done in Attat hospital, where the mean age of the mothers was $28.12 \pm$ 5.14(SD) with age range of 16-45 years 6 while, study conducted in Finoteselam showed most mothers was with age ranged between 20-29 years. This might be due to the fact that these age groups are the most reproductively active age groups.

In this study majority of the mothers $1003(91.2 \%)$ were between $\mathrm{p} 1$ and $\mathrm{p} 4$ while $97(8.8 \%)$ of the mothers had $\geq 5$ delivery history. A study done in Tikur Anbessa specialized hospital, Addis Ababa, showed that, $75 \%$ of mothers were between para 1 and para 4 and $25 \%$ were grand multipara. 8 This shows the number of grand multiparas of this study was smaller than study done in Tikur Anbessa specialized hospital. This difference might be due to Tikur Anbessa is specialized hospital, where a complicated case was referred from different referral hospital and thus might show mothers having $\leq 4$ deliveries had good outcome than from those having $\geq 5$ deliveries history.

In this study mothers who had no ANC follow-up during their pregnancy period had 3.16 times more risk for fetal death than mothers having ANC follow-up (OR 3.159, $\mathrm{P}$-value $=0.000$ ). A similar study conducted in Attat hospital, mothers with ANC followup have good postoperative outcome as compared with mothers with no ANC follow-up $(\mathrm{P}<0.001, \mathrm{COR}=0.16,95 \% \mathrm{CI}=$ $(0.06,0.935)$.

The most common post-operative complications of this study were, vaginal bleeding $5 \%$, severe abdominal pain $4.8 \%$, and surgical site infection $3.5 \%$. A study done in Sultan Qaboos University hospital indicates the leading cause of post-operative complication were respiratory tract infection $2.5 \%$ and post-operative fever $2.1 \% .{ }^{9}$ The variation might be due to the operation theatre's hygiene and the clinician technical skill.

In this study, the leading CS indication was NRFHRP $27.4 \%$, followed by CPD $10.5 \%$, failed induction $10.4 \%$, previous CS scar $9.9 \%$, pre-eclampsia 9.3\%, APH 7.5\% and malposition $4.9 \%$. However, study conducted in Tikur Anbesa specialized hospital showed, repeated CS $32.4 \%$, cephalo-pelvic disproportion 29.2\%, and APH $12.6 \%$ were the leading indications of CS delivery. ${ }^{8}$ This difference could be due to high rate of primary caesarean deliveries in private hospitals of Addis Ababa. A similar study conducted in Adigrat showed, the leading indications were CPD 29.6\%, NRFHR $21.1 \%$, APH $8.6 \%$ and failed induction $5 \% .10$ This could be due to clinician factor or effect of cardio topography.

Ideally in a community with optimal maternal health service, obstructed labor should never happen. But from all of the cases in those study CPD was the common

Table 8. Shows factors associated with fetal outcome at DBRH from January, 2015 to December, 2016.

\begin{tabular}{|c|c|c|c|c|c|}
\hline \multirow[t]{2}{*}{ Variables } & & \multicolumn{2}{|c|}{ Fetal out come } & \multirow[t]{2}{*}{ COR } & \multirow[t]{2}{*}{ P-value } \\
\hline & & Alive & Dead fetus & & \\
\hline \multirow[t]{2}{*}{ ANC follow-up } & YES & 934 & 77 & & \\
\hline & NO & 67 & 22 & 3.159 & .000 \\
\hline \multirow[t]{2}{*}{ Age category } & $17-35 y r s$ & 909 & 89 & & \\
\hline & $36-45 y r s$ & 92 & 10 & .791 & .489 \\
\hline \multirow[t]{2}{*}{ Duration of labor } & $0-12 \mathrm{hrs}$ & 603 & 46 & & \\
\hline & $>12 \mathrm{hrs}$ & 398 & 53 & 1.681 & .015 \\
\hline \multirow[t]{2}{*}{ Maternal hemoglobin } & $4-11 \mathrm{mg} / \mathrm{dL}$ & 165 & 34 & & \\
\hline & $>12 \mathrm{gm} / \mathrm{dL}$ & 836 & 65 & 2.533 & .000 \\
\hline \multirow[t]{2}{*}{ Types of anesthesia } & $\mathrm{GA}$ & 225 & 22 & 1.0148 & .982 \\
\hline & SA & 776 & 77 & & \\
\hline \multirow[t]{2}{*}{ Parity } & P1-p4 & 914 & 91 & .924 & .837 \\
\hline & $\geq \mathrm{p} 5$ & 87 & 8 & & \\
\hline
\end{tabular}


indication for CS. So, this may result in obstructed labor.

\section{Conclusions}

The cesarean section delivery rate is greater than WHO recommendation. The commonest indications of caesarean delivery were NRFHR, CPD, failed induction and previous CS scar. ANC follow up, parity, duration of labor, gestational age, types of $\mathrm{CS}$ and types of anesthesia are the main risk factors for CS and factors that influence maternal and fetal outcomes.

\section{References}

1. WHO, UNICEF, AMDD: Monitoring emergency obstetric care: a handbook;
Geneva: WHO 2009,52.

2. National Collaborating Centre for Women's and Children's Health. Caesarean section Guidline. Royal College of Obstetricians and Gynaecologists, 27 Sussex Place: RCOG Press; 2004.

3. Althabe F, Belizán JM. Cesarean section: the paradox. The Lancet 2006;368:1472-3.

4. Betrán AP, Merialdi M, Lauer JA, et al. Rates of caesarean section: analysis of global, regional and national estimates. Paediatr Perinat Ep 2007;21:98-113.

5. Melaku KY, Tsebay G, Mulat A, Atsede MS. Cesarean Section Rate, Maternal and Fetal Outcome of Birth Following Cesarean Section at Finoteselam Hospital, Northwest Ethiopia. GJMR: (E) Gynecol Obstet 2016;6:3.

6. Moges A, Ademe BW, Akessa GM. Prevalence and Outcome of Caesarean
Section in Attat Hospital, Gurage Zone, SNNPR, Ethiopia. Arch Med 2015;7:4.

7. Ayaba w, Rachel M, Olola O, et al. Trends in cesarean section rates at a large east Africa referral hospital from 2005-2010. OJOG 2012;2:255-61

8. Tadesse E, Adane M, Abiyou M. Caesarean section deliveries at Tikur Anbessa Teaching Hospital, Ethiopia. East Afr Med J 1996;73:619-22.

9. Mathew M, Kumari R, Vaclavinkova V, Krolikowski A. Caesarean sections at Sultan Qaboos University Hospital: A three-year review. J Sci Res Med Sci 2002;4:29-32

10. Kahsay S, Berhe G, Gebremariam A, Betel BB. Determinants of Caesarean Deliveries and its Major Indications in Adigrat Hospital, Northern Ethiopia: A Case Control Study. Epidemiology (sunnyvale) 2015;5:192. 